\title{
Comparative Study of Chinese and Foreign Environmental Performance Audit Method
}

\author{
Jinyu Tian ${ }^{1,}$, Yuan Jiang ${ }^{2, b}$ \\ ${ }^{1}$ North China Electric Power University, Baoding, Hebei 071003, China; \\ ${ }^{2}$ North China Electric Power University, Baoding, Hebei 071003, China \\ a571368975@qq.com, bjy9303@126.com
}

Keywords: Environmental audit; performance audit; environmental performance audit method; comparative study.

\begin{abstract}
Along with the rapid development of China's economic and social, haze, soil pollution and water pollution become the center of the current topic. From a certain extent, the heat of the environmental topics reflects the strong desire for a better environment of us. The protection and governance of environment, should not only focus on the effect, but also focus on efficiency. Only with economy, efficiency, effect, it can become a form of sustainable development. Environmental performance audit arises at the historic moment and develops continuously. This paper takes environmental performance audit method as the research object. Firstly, the research background, significance, definition, objective and criterion of environmental performance audit method are discussed in the paper. Then, through the comparison of the Chinese and foreign environmental performance audit methods, the paper expounds the application conditions and advantages and disadvantages of different methods, and finally puts forward some suggestions that help us improve environmental performance audit.
\end{abstract}

\section{Introduction}

Environmental problem is known as the eternal theme of human society. Environmental issues appear with the existence and development of human society economic activities. Human is both the product and the modifier of the environment. Starting from the civilized society, quickening the pace of transforming the environment, leads to the development of the environmental problems at an unprecedented rate.

Environmental performance audit method research arises at such background that the global environmental protection is extremely urgent. The emergence of environmental problems and the degree of deterioration make the status of environmental performance audit prominent day by day. How to play better role of environmental performance audit, and finally achieve the objectives of the environmental performance auditing makes the study of environment performance audit method become crucial.

\section{Overview of environmental performance audit method}

\subsection{The concept of audit method.}

In order to ensure the smoothly implementation of audit, and achieve the audit goals, the various means used in the process of auditing are referred to as audit methods.

Audit methods are divided into the scene of the prior audit activities, environmental auditing activities and post audit activities by the international institute of internal auditors. Classifying audit methods from different angles is beneficial to auditors choosing a suitable audit method according to different stages of the audit environment in order to achieve the desired objective of audit. In addition, audit methods can also be distinguished from economy, efficiency and effectiveness. Of course, some audit methods can achieve several audit goals at the same time, such as cost benefit method or environmental optimal value model, which can play a good role in promoting the achievement of audit goals. 


\subsection{The characteristics of the environmental performance auditing methods.}

As for a fusion of environmental audit and performance audit, environmental performance auditing method has its own characteristics on the basis of inheriting the essential connotation of audit. Specific contents are as follows:

Firstly, the complexity. Environmental performance auditing involves all aspects of the environment, and needs the support of multiple disciplines. Mathematical statistics, geography, environmental engineering, sociology, etc. are involved. Possessing characteristics of different disciplines makes environmental performance auditing a cross major, with high complexity and strong comprehensive.

Secondly, combining qualitative method with quantitative method. Forms of environmental performance are various, who both have available value and the value difficult to quantitative, not only have macroscopic benefits, also microscopic benefits. It is difficult to contain all areas of environmental performance audit in a measurement model. Therefore, the choice of the environmental performance auditing methods must merge both.

Third, the diversity of audit approaches. Environmental performance audit involves many aspects of the audit; there are both the content of the economy and profitability and efficiency of the content. The requirement of different aspects make the diversity of the method. It may be need a variety of methods even for the same type or aspect of the audit content, due to the audit environment.

\subsection{The implementation principle of the environmental performance auditing method.}

As for the implementation principle, we need to master the following points:

First of all, the maneuverability. Maneuverability is one of the basic requirements of audit method. Environmental performance audit, although has the characteristic of multidisciplinary cross, for the auditor, it is meaningless if that is difficult to put into practice even though advanced. Method emphasized on the implementation of the cost benefit idea, except for some must implement the control test and substantive test, audit need to be to achieve benign balance between efficiency and audit effectiveness in many aspects.

And then, implementing different methods of audit according to the different environmental performance audit object. Different audit object involves different audit objectives. Water, air, forest, grassland, this different audit object with different characteristics, is hard of a language. At the same time, on the same audit object, audit method of different point may also be different. For example, we can choose the cost recovery method, also can choose market value method to audit a certain period of the environmental degradation cost of forest resources. Choice of the method must combine the field situation, choose both the effect and efficiency, and balance the income and cost.

Finally, environmental performance auditing implementation process needs to be sustainable. Environmental project's impact on the environment has process, sustainability and diversity. Environmental performance auditing is difficult to play the role in the construction of ecological civilization just for post audit. Environmental performance audit, therefore, need to build a dynamic and continuous process audit program, which makes environmental performance audit meaningful in advance, matter and afterwards.

\section{The comparison of environmental performance audit method}

\subsection{Canadian investigation method.}

Investigation method is often used by Office of the Auditor General. Investigation method is used to collect information, through the implementation of standardized procedures (such as a questionnaire or structured interview) in order to obtain information that is more than 25 individual instances, whose purpose is to make summary to survey items by comprehensive statement ${ }^{[1]}$. It is a creative and persuasive evidence collection method, which can be used to collect data on a wide variety of topics, divided into two categories, comprehensive survey and sampling survey. 
Comprehensive survey refers to all the members of the general, such as all hospitals, government departments, institutions or non-government institutions, or the members of the public ${ }^{[2]}$. When you need to accurately provide audit relevant information, to avoid the uncertainty and the purpose is to check the compliance of relevant standards and comparison between public institutions, a full investigation is applies.

Auditors may consider using the sampling survey method if the overall size of investigation is too big and it is difficult to conduct a comprehensive investigation. Sampling survey method need to balance the relationship between the audit efficiency and audit quality ${ }^{[3]}$.

Investigation method generally includes 11 steps:

(1) the investigation plan;

(2) sampling;

(3) reliability and validity of survey information .

(4) confirmed;

(5) the advantages and disadvantages of different personal data acquisition mode;

(6) the development and validation data collection tools;

(7) anonymity and confidentiality;

(8) the integrity of the investigation;

(9) the management, processing and analysis of survey data;

(10) advanced test data collection tool;

(11) the management of no response.

Investigation method can save time, money and manpower, and is easy to operate. At the same time, the results of the survey are easy to be quantified, facilitate statistical processing and analysis, which can be used to undertake large-scale survey. These advantages make this method has a broad application space in the performance audit ${ }^{[4]}$.

\subsection{The U.S. synthesis evaluation.}

In the process of discussing official business, Government Accountability Office serves congress decision makers by providing information about the analysis of problems of audit. Synthesis evaluation is well adapted to the requirement. Synthesis evaluation refers to the systematic procedure that starts from some separated studies, and organizes their studies together. Its contents include:

(1) determine the problems of a project;

(2) identify and collect the existing research to these questions, and evaluate these studies based on the quality of these studies and on the basis of evidence to support the effectiveness of the study.

The ultimate goal of evaluation methods is to provide information of research problems. Using the evaluation method must satisfy two basic conditions: one is answering the question does not need to collect original data; the second is already existing a lot of related research. The method implementation steps are as follows:

(1) choose the problem to be solved;

(2) collect related data;

(3) select related research;

(4) strict scrutiny for related research;

(5) determine appropriateness of carrying out the evaluation.

(6) implement comprehensive evaluation;

(7) report the findings.

Synthetic method can provide relatively low cost, strong comprehensive and timely information, and enhance the convincing of studying, at the same time, collect the separation from multiple research information about a specific problem together to form a common knowledge base on that particular topic.

\subsection{The British method of analytical framework.}

Analytical framework method is a major change in the UK performance audit method, throughout the whole process of performance audit. The main purpose of this method is to guide the performance audit teams with relatively consistent way to evaluate the performance of the auditees ${ }^{[5]}$. This method 
is composed of a series of problems, in 2011, the appendix 3 of the British "performance audit manual" lists the problem of the various steps and factors need to concern. In brief, analytical framework has six steps, respectively in the audit plan phase (step 1-3) and on-site audit phase (step 4-6), these six series also can be used as the framework of environmental performance audit report:

(1)establish "optimal" state. In determining the best performance, it is necessary to determine the limitation of "reasonable" and understanding;

(2) list all the resources related to the audit projects;

(3) judge output and effect should be achieved according to the existing resources;

(4) judge performance (through internal comparison);

(5) draw the audit conclusion according to the use of existing resources to achieve the performance (through external comparison);

(6) suggest how to improve the performance of the audit.

\subsection{Environmental performance audit method in our country.}

At present, interview method, observation method, analysis method and other traditional methods of performance audit is widely applied in our country's environmental performance audit. Usage of the Qingzang-tibet railway environmental protection funds audit, water pollution prevention and control of funds audit in Shanxi Province are typical cases of this kind of audit method ${ }^{[6]}$.

At the same time, our country also uses some innovative environmental performance audit methods, such as geographic information systems (GIS), layer overlay technology and in combination with GPS, geographic information support software and in combination with GPS, etc.

\section{References to the method of foreign environmental performance audit}

\subsection{Issue authoritative environmental performance auditing methods manual.}

As for Britain, the auditor successively promulgated "the handbook of performance audit", performance standards, guidelines, performance audit framework of various audit techniques and other normative documents three times to carry out performance audit, to make a provision for the principle of performance audit, and put forward the guiding opinions on how to carry out performance audit, how to implement the audit and tracking check, and how to carry out performance audit quality control. These standards and guidelines have greatly increased the domestic level of environmental performance audit. In contrast, the present situation in our country, authoritative file has not issued, which is extremely unfavorable to promote the development of environmental performance auditing. As a result, authority environmental performance auditing method manual to regulate and guide the environmental performance auditing in our country, will develop the environmental performance audit.

\subsection{Combine the qualitative and quantitative method together.}

An important characteristic of environmental performance auditing is facing huge amounts of data. Only using qualitative method will be difficult to get objectively and persuasive audit conclusion. The United Nations international accounting and reporting standards intergovernmental expert working group puts forward "ecological efficiency" to evaluate, and Canadian using computer modeling, process research, and other advanced methods of collecting audit evidence for audit. These methods are worth learning and reference in China.

\subsection{Do environmental performance audit work from the comprehensive perspective.}

There is a comprehensive performance evaluation and comprehensive regional assessment in British environmental performance auditing method, a synthesis evaluation in United States and Canada. From this developing country, we can see that comprehensive is a kind of trend, is also a guarantee of the final verification results. Strengthening the cultivation of the comprehensive, integrated thinking, will help us to arrive in a higher level of development of the undertaking of environmental performance audit. 


\section{Conclusion}

Foreign environmental performance auditing originated in the late 1960's, which is 20 years earlier than domestic. Chinese and foreign environmental performance auditing method selection and application environment are different, which leads the Chinese and foreign environmental performance auditing methods showing their own features. Commonness and characteristics make the environmental performance auditing methods contrast at home and abroad. Different countries comparative study on the methods of environmental performance audit helps us know our state more clearly, and provides more choices for the research of method of environmental performance audit in our country.

\section{References}

[1]. Office of the Auditor General of Canada. Report of the Commissioner of the Environment and Sustainable Development. 2014,9:5-27.

[2]. Office of the Auditor General of Canada. Departmental Progress in Implementing Sustainable Development Strategies.2014, 9:10-25.

[3]. GSA's Courthouse Projects Illustrate Opportunities to Improve Management Practices and Analyze Environmental Outcomes.2015, 2:30-35.

[4]. Office of the Auditor General of Canada. Marine Navigation in the Canadian Arctic.2015, 9:5-21.

[5]. Rudi Turksema. Planning and Selecting Performance Audits at the N-etherlands Court of Audit. International Journal of Government Auditing, 2007(7).

[6]. RidgwMHallJr. The Evolution and New Directions in Environmental Auditing and Compliance Management[J].Natural Resources \& Environment,2009,24(2):3-8. 